\title{
Preliminary Evaluation of Novel Triglyceride-Based Nanocomposites for Biomedical Applications
}

\author{
Raimundo R. de Almeida, ${ }^{a}$ Juan Gallo, ${ }^{b}$ Aiêrta C. C. da Silva, ${ }^{a}$ Ana K. O. da Silva, ${ }^{a}$ \\ Otilia D. L. Pessoa, ${ }^{a}$ Tamara G. Araújo, ${ }^{c}$ Luzia K. A. M. Leal, ${ }^{c}$ Pierre B. A. Fechine, ${ }^{d}$ \\ Manuel Bañobre-López ${ }^{*, b}$ and Nágila M. P. S. Ricardo*,a
}

${ }^{a}$ Departamento de Química Orgânica e Inorgânica, Universidade Federal do Ceará, Campus do Pici, 60455-760 Fortaleza-CE, Brazil

${ }^{b}$ Advanced (magnetic) Theranostic Nanostructures Lab, International Iberian Nanotechnology Laboratory, Av. Mestre José Veiga s/n, 4715-330 Braga, Portugal

${ }^{c}$ Departamento de Farmácia, Universidade Federal do Ceará, Rua Capitão Francisco Pedro, 1210, 60430-170 Fortaleza-CE, Brazil

${ }^{d}$ Departamento de Química Analítica e Físico-Química, Universidade Federal do Ceará, Campus do Pici, 60444-900 Fortaleza-CE, Brazil

\begin{abstract}
This work describes the development and characterization of triglyceride-based magnetic nanocomposites for application in magnetic hyperthermia and controlled drug delivery. The magnetic solid lipid nanocomposites (MSLN) constituted by mixtures of trilaurin-tricaprylin and trilaurin-tricaprin have been successfully obtained by emulsification-solvent evaporation method. The developed MSLNs were subjected to an external oscillating magnetic field and showed significant hyperthermia. The samples were exposed to frequencies of 688 and $869 \mathrm{kHz}$ causing, respectively, a temperature increase of 15.5 and $22.7^{\circ} \mathrm{C}$ (trilaurin-tricaprylin) and 17.3 and $26.1{ }^{\circ} \mathrm{C}$ (trilaurin-tricaprin). Also, in vitro assays in the absence of magnetic field showed that the triglyceride-based formulations were able first to encapsulate and then to sustained release an antitumoural hydrophobic drug. After $72 \mathrm{~h}$ of assay trilaurin-tricaprylin and trilaurin-tricaprin released 73 and 55\% of their cargo, respectively. In addition, MSLN exhibited low in vitro cytotoxic activity against human neutrophils.
\end{abstract}

Keywords: lipid mixture, magnetic hyperthermia, drug delivery, oncocalyxone-A

\section{Introduction}

Nanotechnology is an expanding sector and the use of superparamagnetic iron oxide nanoparticles (SPIONs) is attracting increasing attention in several areas. SPIONs are widely employed for biotechnological applications through the development of magnetic systems for use in: cell separation, as contrast agents for magnetic resonance imaging (MRI), magnetic hyperthermia, targeted bioactive compounds delivery and biosensors. ${ }^{1-4}$ Such applications explore the biggest advantages of using SPIONs: biocompatibility and satisfactory magnetic response at applied magnetic field (superparamagnetic character). ${ }^{5,6}$

*e-mail: naricard@ufc.br, manuel.banobre@inl.int
The surface of the magnetic nanoparticles should be modified, not only in order to prevent oxidation and aggregation, but also to provide colloidal stability, reduced magnetic susceptibility, as well as to expand the effectiveness of cellular uptake and biodistribution. The hydroxyl groups present on the surface of nanoparticles can function as an anchor point for various types of compounds such as oleic acid, which is commonly used in the synthesis of magnetic ferrofluids. The criteria adopted to select the appropriate coating of magnetic nanoparticles depends mainly on the intended application. In the case of this research, magnetic nanoparticles made of iron oxide were coated with oleic acid $\left(\mathrm{Fe}_{3} \mathrm{O}_{4} @ \mathrm{OA}\right)$ for subsequent incorporation into lipid carriers. ${ }^{7-9}$

The lipid carriers have been widely used as they also possess excellent characteristics such as biocompatibility 
and versatility, and they have been proposed for the delivery of bioactive compounds by oral, intravenous, topical and parenteral routes. ${ }^{10,11}$

The solid lipid nanoparticles (SLNs) emerged in the early 90's and currently are alternative encapsulation systems and carriers of active compounds to polymeric nanoparticles (nanospheres and nanocapsules). The SLNs are colloidal dispersions containing a surfactant agent and a matrix composed of solid lipids at room and corporal temperature. ${ }^{12,13}$

SLNs present some advantages in comparison to conventional carrier systems such as low toxicity, efficient incorporation of hydrophobic bioactive compounds in their lipid core, the ability to influence the release profile of their cargo from the solid matrix and easy large-scale production..$^{14,15}$

Several methods are employed in the SLNs preparation, however the method of emulsification-solvent evaporation is usually applied when the bioactive compound has low solubility in the lipid or it is thermosensitive. ${ }^{16,17}$

The common lipids used to obtain the SLNs are triglycerides, ${ }^{12}$ fatty acids ${ }^{13}$ and waxes. ${ }^{14}$ Among the triglycerides, emphasis is placed on trilaurin, tricaprin and tricaprylin, which were selected to form the lipid matrix of the nanosystems synthesized in this work. Some research confirms the potential of these lipids in the bioactive encapsulation. ${ }^{18-20}$

Thus, combining the properties of the SLNs and SPIONs, the magnetic solid lipid nanoparticles (MSLNs) appear as a promising system for use in magnetic hyperthermia and drug delivery of bioactive molecules at specific sites, which can be triggered by the thermomagnetic action. ${ }^{21-23}$ It is noteworthy that MSLNs can also be used in diagnostic procedures via magnetic resonance imaging technique (MRI) because magnetite is an excellent contrast agent (T2 type). In addition, such systems are applied in cancer treatment, since the heat generated in hyperthermia by itself produces an antitumor action..$^{24,25}$

Magnetic hyperthermia has shown great potential for the development of effective methods for the cancer treatment combined with conventional therapies such as radiation and chemotherapy. The temperature increase at range from 42 to $44{ }^{\circ} \mathrm{C}$ (temperature range used in clinical treatments by hyperthermia) significantly reduces cell viability of the tumor cells. ${ }^{26,27}$

In this context, oncocalyxone-A (onco-A), a quinone (Figure 1) obtained from the Auxemmaoncocalyx Taub. plant, was selected as a bioactive model compound for the purpose of this study. The bioactive compound selected has several pharmacological properties such as cytotoxic activity, analgesic, anti-inflammatory, antioxidant and anti-tumor activity against three human tumor cell lines: Sarcoma 180, Leukemia HL-60 and L1210 Leukemia. ${ }^{28}$<smiles>COC1=CC(=O)C2=C(C1)C1=CC3=C(CO)CC[C@H](O)[C@@]3(C)CC12</smiles>

Figure 1. Oncocalyxone-A chemical structure.

It is worth mentioning that, although there are scientific papers describing the development of solid lipid nanoparticles (NLSM), no previous work involving the use of lipid mixtures (trilaurin, tricaprin and tricaprylin) was found in the literature. Thus, herein we report the development of MSLN containing onco-A for in vitro release as well as to explore this system in heating tests for magnetic hyperthermia.

\section{Experimental}

\section{Materials}

Iron(II) chloride tetrahydrate (Sigma-Aldrich), iron(III) chloride hexahydrate (Sigma-Aldrich), ammonium hydroxide (Sigma-Aldrich), trilaurin (TCI Europe), tricaprin (TCI Europe), tricaprylin (TCI Europe), oleic acid (Sigma-Aldrich), Tween 20 (Sigma-Aldrich), chloroform (analytical grade or better: Sigma-Aldrich), hexane (analytical grade or better: Sigma-Aldrich), acetonitrile (HPLC grade: Tedia).

\section{Synthesis and characterization of $\mathrm{Fe}_{3} \mathrm{O}_{4} @ \mathrm{OA}$ nanoparticles}

Hydrophobic nanoparticles of magnetite $\left(\mathrm{Fe}_{3} \mathrm{O}_{4} @ \mathrm{OA}\right)$ were prepared by coprecipitation method adapted. ${ }^{29}$ Briefly, $9.2 \mathrm{~g}$ of iron(II) chloride tetrahydrate and $15 \mathrm{~g}$ of iron(III) chloride hexahydrate were dissolved in $250 \mathrm{~mL}$ of deionized water and stirred for $10 \mathrm{~min}$ at $50{ }^{\circ} \mathrm{C}$. After $10 \mathrm{~min}, 30 \mathrm{~mL}$ of $\mathrm{NH}_{4} \mathrm{OH}\left(12 \mathrm{~mol} \mathrm{~L}^{-1}\right)$ were added resulting in a dark precipitate $\mathrm{Fe}_{3} \mathrm{O}_{4}$. Then $2.5 \mathrm{~mL}$ of oleic acid was added and the mixture was heated at $80^{\circ} \mathrm{C}$ for $1 \mathrm{~h}$. Excess $\mathrm{NH}_{4} \mathrm{OH}$ and oleic acid $(\mathrm{OA})$ were removed by magnetic separation of $\mathrm{Fe}_{3} \mathrm{O}_{4} @ \mathrm{OA}$ with the use of a magnet, followed by the decantation of the supernatant and the redispersion of the solid in fresh solvent. The washing procedure was repeated five times with deionized water and four times with hexane. Finally, the $\mathrm{Fe}_{3} \mathrm{O}_{4} @ \mathrm{OA}$ nanoparticles were dried, dispersed in chloroform and stored at room temperature. 
The concentration of $\mathrm{Fe}_{3} \mathrm{O}_{4}$ in the final dispersion was determined by thermogravimetric analysis (TGA), where the ferrofluid was heated $25-700{ }^{\circ} \mathrm{C}$ in $\mathrm{N}_{2}$ atmosphere and the heating rate was $10{ }^{\circ} \mathrm{C} \mathrm{min}^{-1}$, resulting in a concentration of $92 \mathrm{~g} \mathrm{~L}^{-1}$. The $\mathrm{Fe}_{3} \mathrm{O}_{4} @ \mathrm{OA}$ nanoparticles were also characterized by transmission electron microscopy (JEM 2100, JEOL $^{\circledR}$ USA) and powder $\mathrm{X}$-ray diffraction (X'Pert diffractometer PRO, PANalytical) set at $45 \mathrm{kV}$ and $40 \mathrm{~mA}$ and equipped with $\mathrm{Cu} \mathrm{K} \alpha$ radiation $(\lambda=1.541874 \AA$ ) using Bragg-Brentano geometry of $2 \theta$ range from 20 to $100^{\circ}$ with a scan speed of $0.006^{\circ} \mathrm{s}^{-1}$.

\section{Synthesis of magnetic solid lipid nanoparticles (MSLNs)}

Magnetic solid lipid nanoparticles (MSLNs) were synthesized by the method of emulsification-solvent evaporation. In the preparation of the organic phase (OP), $270 \mu \mathrm{L}$ of the suspension $\mathrm{Fe}_{3} \mathrm{O}_{4} @ \mathrm{OA}$ were dispersed in $730 \mu \mathrm{L}$ chloroform containing $500 \mathrm{mg}$ of lipid and $2 \mathrm{mg}$ of oncocalyxone-A. Then the aqueous phase (AP) was prepared by dissolving $200 \mathrm{mg}$ of Tween $20 \mathrm{in} 10 \mathrm{~mL}$ of deionized water. Subsequently, the OP was added to AP at room temperature and homogenized with Vortex IKA ${ }^{\circledR}$. This pre-emulsion was sonicated in an ultra sound (Branson W-450D Sonifier ${ }^{\circledast}$ Model) with 50\% amplitude for $2 \mathrm{~min}$ and pulse (30 seconds on / 10 seconds off). After this step, this dispersion was subjected to a rotary evaporator (Buchi ${ }^{\circledR}$ $\mathrm{R} 100)$ under vacuum at $35^{\circ} \mathrm{C}$. After the organic solvent evaporation and the solidification of lipids the MSLNs were formed. Two different triglyceride mixtures were formulated to obtain MSLNs: (i) tricaprin/trilaurin and (ii) tricaprylin/ trilaurin, both with a triglyceride ratio $1: 1(\mathrm{~m} / \mathrm{m})$, leading to samples MSLN1 and MSLN2, respectively.

\section{Physicochemical characterization of MSLNs}

The hydrodynamic diameter and polydispersion of the MSLN1 and MSLN2 aqueous dispersions were determined by dynamic light scattering (DLS) using a Horiba ${ }^{\circledR}$ SZ-100 nanoparticle analyzer. The MSLN dispersions were diluted in deionized water with the ratio $1: 1000(\mathrm{v} / \mathrm{v})\left(\mathrm{MSLN}: \mathrm{H}_{2} \mathrm{O}\right)$ and analyzed at a fixed angle of $90^{\circ}$ at $25^{\circ} \mathrm{C}$. The surface charge of the MSLNs was evaluated by zeta potential. The results of both analyses were expressed as the average of three determinations.

The morphology of MSLNs was analyzed by scanning electron microscopy (SEM Quanta 650 FEG, FEI $^{\circledR}$ Company). For the sample preparation, an aliquot of the MSLNs dispersions was diluted in deionized water in the ratio 1:1000 (v/v) (MSLN: $\left.\mathrm{H}_{2} \mathrm{O}\right)$. Then, $50 \mu \mathrm{L}$ of this dilution was deposited on a silicon wafer and dried under vacuum.
Differential scanning calorimetry (DSC) was employed to study thermal behavior of freeze dried MSLNs samples and the thermograms were performed using a differential scanning calorimeter model DSC-50 (Shimadzu $\left.{ }^{\circledR}\right)$. The thermal analysis of MSLNs was conducted in $\mathrm{N}_{2}$ atmosphere at a flow rate of $40 \mathrm{~mL} \mathrm{~min}{ }^{-1}$, a temperature range of -20 to $150^{\circ} \mathrm{C}$ and a linear increase of $10^{\circ} \mathrm{C} \mathrm{min}^{-1}$.

The powder X-ray diffraction (XRD) data of MSLNs were obtained on a diffractometer X'Pert PRO (PANalytical ${ }^{\circledR}$ ) set at $45 \mathrm{kV}$ and $40 \mathrm{~mA}$ and equipped with $\mathrm{Cu}$ Ka radiation $(\lambda=1.541874 \AA$ ) using Bragg-Brentano geometry of $2 \theta$ range from 20 to $100^{\circ}$ with a scan speed of $0.006^{\circ} \mathrm{s}^{-1}$.

\section{Magnetic properties}

The hysteresis loops of $\mathrm{Fe}_{3} \mathrm{O}_{4} @ \mathrm{OA}$ and MSLNs were measured using a vibrating sample magnetometer (VSM, EV9 MicroSense ${ }^{\circledR}$ ). The magnetization as a function of the applied magnetic field was collected at $300 \mathrm{~K}$ in the magnetic field range from -20 to $20 \mathrm{kOe}$. The magnetization values were expressed per mass of the vacuum dried magnetic material.

\section{Magnetic hyperthermia}

The magnetic hyperthermia curves were acquired in a DM100 instrument (Nanoscale Biomagnetics ${ }^{\circledR}$ ) at a frequency of 688 and $869 \mathrm{kHz}$ and at an intensity of the magnetic field of $200 \mathrm{Oe}$. The samples were placed in $2 \mathrm{~mL}$ vials and measured in the dispersion aqueous form.

\section{In vitro drug release studies}

In order to evaluate the release profile of the oncocalyxone-A from the lipid core of the MSLNs, release kinetics experiments were performed. The system used in this experiment consisted of a donor compartment where $1 \mathrm{~mL}$ of the MSLNs formulation under study was added and an acceptor compartment prepared with $50 \mathrm{~mL}$ of buffer phosphate solution at $\mathrm{pH} 7.4$ which was in the dilution sink condition. For release assays, $1 \mathrm{~mL}$ of aqueous oncocalyxone-A, MSLN1 or MSLN2 $\left(0.2 \mathrm{mg} \mathrm{mL}^{-1}\right)$ was added to the donor compartment. A cellulose membrane (Microcon-Millipore ${ }^{\circledR}$ ) with a molecular exclusion pore $1 \mathrm{kDa}$ was used to separate both compartments. Aliquots $(1 \mathrm{~mL})$ were collected after $30 \mathrm{~min}$ of experiment and at intervals of 1 hour for the first eight hours. After, aliquots were collected each $24 \mathrm{~h}$ to complete the total test in $72 \mathrm{~h}$ (3 days). The obtained aliquots were analyzed by high performance liquid chromatography (HPLC) for subsequent 
determination of the concentration values which converted into percentage of the oncocalyxone-A released which were later plotted on a graph of cumulative percentage bioactive released versus time (hours). This assay provides the bioactive ability to cross the pores of the membrane that separates the donor compartment from the acceptor. However, MSLN particles are unable to pass through this membrane and therefore it is possible to observe the tunneling effect of the bioactive release rate. The release experiments were performed in triplicate at $37 \pm 1{ }^{\circ} \mathrm{C}$. The HPLC analyzes were conducted on a chromatograph $\left(\right.$ Shimadzu $\left.^{\circledR}\right)$, model LC-10AD, Phenomenex ${ }^{\circledR}$ equipped with a Luna C-18 column $(5 \mu \mathrm{m}, 250 \times 4.6 \mathrm{~mm})$ with a flow rate of $1 \mathrm{~mL} \mathrm{~min}{ }^{-1}$ at $40{ }^{\circ} \mathrm{C}$. The mobile phase of $\mathrm{CH}_{3} \mathrm{CN} / \mathrm{H}_{2} \mathrm{O}(1: 1, \mathrm{v} / \mathrm{v})$ was used with isocratic elution and UV detection (SPD-20A/UV-Vis) at $280 \mathrm{~nm}$.

\section{Drug release kinetics mechanisms}

To analyze the mechanism of onco-A release from these MSLNs systems, the in vitro dissolution data were fitted to various mathematical models, such as, zero order, pseudo-first order (Higuchi) and Korsmeyer-Peppas models (equations 1-3). . $^{30,31}$

Zero-order model: $\mathrm{Q}=\mathrm{Kt}$

Higuchi model: $\mathrm{Q}=\mathrm{Kt}^{1 / 2}$

Korsmeyer-Peppas model: $\mathrm{M}_{\mathrm{t}} / \mathrm{M}_{\infty}=\mathrm{Kt}^{\mathrm{n}}$

where $\mathrm{Q}$ is the percentage of bioactive release at time $\mathrm{t}$, $M_{t} / M_{\infty}$ represents the fraction of bioactive released in time $\mathrm{t}, \mathrm{K}$ is the release constant and $\mathrm{n}$ is the release exponent that specifies the bioactive release mechanism.

The Korsmeyer-Peppas model has been employed in the in vitro bioactive release behavior analysis of various formulations to distinguish between various release mechanisms: Fickian release (diffusion-controlled release), which occurs when $\mathrm{n} \leq 0.5$; Case-II transport, which involves polymer dissolution and polymeric chain enlargement or relaxation, occurs when $\mathrm{n} \geq 1.0$; and non-Fickian release (anomalous transport), where an $\mathrm{n}$ value between 0.5 and 1.0 involves a combination of the diffusion mechanisms and Case II transport.

\section{Oncocalyxone-A encapsulation efficiency}

The MSLNs formulations were subjected to the magnetic separation for determination of the free oncocalyxone-A amount. Then, the non-magnetic aqueous fraction was analyzed by HPLC. The onco-A entrapped in MSLNs systems was determined by the difference between the initial amount of bioactive added to the MSLN formulations and the free amount observed. In this way, the encapsulation efficiency (EE) was determined through the equation 4 :

$\mathrm{EE}=[(\mathrm{B}-\mathrm{A}) / \mathrm{B}] \times 100$

where A: unencapsulated amount of bioactive in MSLN nanoparticles and B: initial amount of bioactive in MSLN formulations.

Cytotoxicity study: determination of lactate dehydrogenase (LDH) assay

Human neutrophils were isolated by Lucisano and Mantovani's method ${ }^{32,33}$ with slight modifications. Cells pellets were suspended in Hank's balanced salt solution (HBSS) containing 80-90\% neutrophils with viability of $90 \pm 2.0 \%$ established by Trypan Blue exclusion test. Human neutrophils $\left(2.5 \times 10^{6}\right.$ cells $\left.\mathrm{mL}^{-1}\right)$ were incubated $\left(15\right.$ min at $37^{\circ} \mathrm{C}$ ) with HBSS (non-treated cells), Triton X-100 (0.2\% (v/v), standard cytotoxic), MSLN1 and MSLN2 samples (pure and with dilutions of 1:10, 1:50, 1:100 (v/v)). The lactate dehydrogenase (LDH) activity was determined by a commercially available method (LDH liquiform of Labtest Diagnosis).

\section{Statistical analysis}

The results are expressed as mean \pm standard deviation (SD). The statistical significance of differences between groups was determined by one-way analysis of variance (ANOVA), followed by Tukey for multiple comparisons as a post hoc test. The significance level was set at $p<0.05$.

\section{Results and Discussion}

\section{MSLN's characterization}

The MSLNs containing magnetite nanoparticles coated with oleic acid $\left(\mathrm{Fe}_{3} \mathrm{O}_{4} @ \mathrm{OA}\right)$ and oncocalyxone-A as bioactive compound were prepared by emulsification-solvent method. The use of oleic acid in the coating of magnetite nanoparticles emerged as a strategy to reduce oxidation and the degree of aggregation of $\mathrm{Fe}_{3} \mathrm{O}_{4}$ nanoparticles as well as to ensure compatibility with the organic phase used in the preparation of MSLNs. The nanoparticles samples MSLN1 and MSLN2 which lipid matrix was composed of lipids mixtures trilauri + tricaprin and tricaprylin + trilaurin, respectively, had an average diameter of $176 \pm 8 \mathrm{~nm}$ (MSLN1) 
and $177 \pm 9 \mathrm{~nm}$ (MSLN2) and polydispersity index (PDI) of $0.10 \pm 0.24(\mathrm{MSLN} 1)$ and $0.18 \pm 0.03$ (MSLN2). These results did not show significant difference in average diameter between formulations and furthermore a narrow particle size distribution was observed. The zeta potential measurements showed values of surface charge of $-52.9 \pm 3.8$ and $-54.5 \pm 1.1 \mathrm{mV}$ for MSLN1 and MSLN2, respectively, indicating that the high colloidal stability of the MSLNs observed in water solution can be explained by the strong electrostatic repulsion between particles. The observed negative charge can be explained by the chemical composition of the lipids mixtures, which can be dissociated on the particle surface. Figure 2A shows the TEM micrograph $\mathrm{Fe}_{3} \mathrm{O}_{4} @ \mathrm{OA}$ nanoparticles obtained by chemical co-precipitation that was used to determine the mean size of about $8 \mathrm{~nm}$ (Figure 2B). Through the SEM micrographs, MSLN1 and MSLN2 (Figures 2C and 2D) did not display granular artifacts with dark contrast deposited on the surface of the silicon wafer, a fact that would demonstrate the presence of magnetic nanoparticles non-encapsulated.

X-ray diffraction (XRD) confirmed that the crystallographic phase of the magnetic nanoparticles in the ferrofluid was that of magnetite, $\mathrm{Fe}_{3} \mathrm{O}_{4}$ (Figure 3). The diffraction peaks at $2 \theta 30.1 ; 35.5 ; 43.1 ; 53.75 ; 57.2$ and $62.85^{\circ}$ correspond to the characteristic crystal planes of $\mathrm{Fe}_{3} \mathrm{O}_{4}$ structure (2 200$),\left(\begin{array}{lll}3 & 1 & 1\end{array}\right),\left(\begin{array}{lll}4 & 0 & 0\end{array}\right),\left(\begin{array}{lll}4 & 2 & 2\end{array}\right),\left(\begin{array}{lll}5 & 1 & 1\end{array}\right)$, respectively. ${ }^{34}$ Those diffraction peaks can be identified also in the XRD patterns of the samples MSLN1 and MSLN2, that together with the SEM analysis showing the absence of magnetite nanoparticles alone, point to the successful incorporation of the magnetite nanoparticles into the lipid core. Extra peaks can be also observed in the XRD patterns of MSLN1 and MSLN2 between 20 and 30 ${ }^{\circ}$ that are associated to the polymorphism of the lipid matrix.

The DSC curve of the freeze-dried MSLN2 sample (Figure 4) showed a single endothermic event corresponding to the fusion of the lipid matrix at $\mathrm{T}=41{ }^{\circ} \mathrm{C}\left(\Delta \mathrm{H}=73 \mathrm{~J} \mathrm{~g}^{-1}\right)$. The DSC curve MSLN1 showed two endothermic events with $\mathrm{T}=9.5^{\circ} \mathrm{C}\left(\Delta \mathrm{H}=57 \mathrm{~J} \mathrm{~g}^{-1}\right)$ and $\mathrm{T}=42{ }^{\circ} \mathrm{C}\left(\Delta \mathrm{H}=88 \mathrm{~J} \mathrm{~g}^{-1}\right)$. This result may be related to the solubility of the molecules of the liquid lipid (tricaprylin) in the solid lipid (tricaprin), leading to a phase separation and the formation of nanocompartments (domains) of oil inside the solid lipid matrix in MSLN1. ${ }^{35,36}$
(A)

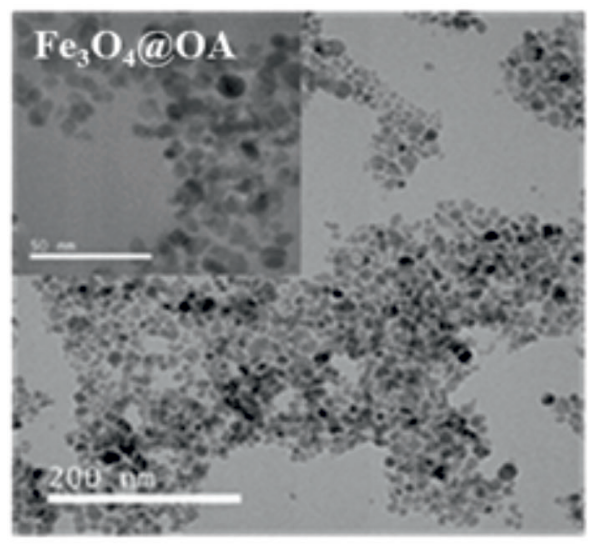

(C)

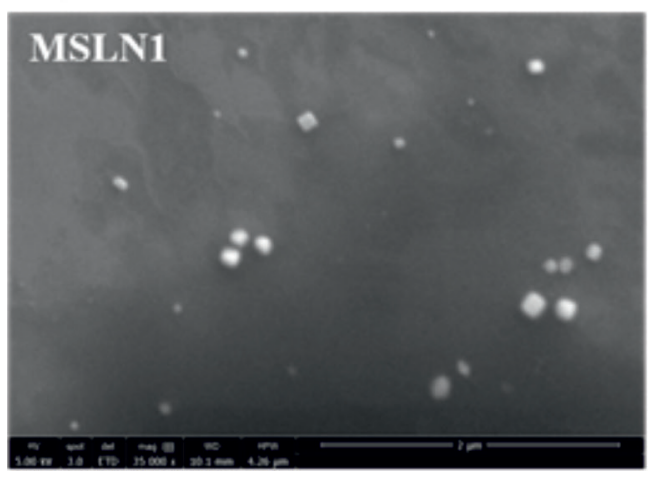

(B)

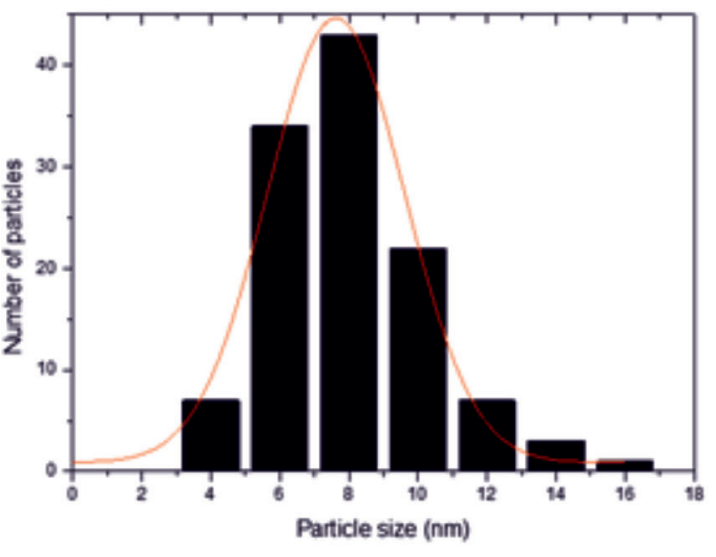

(D)

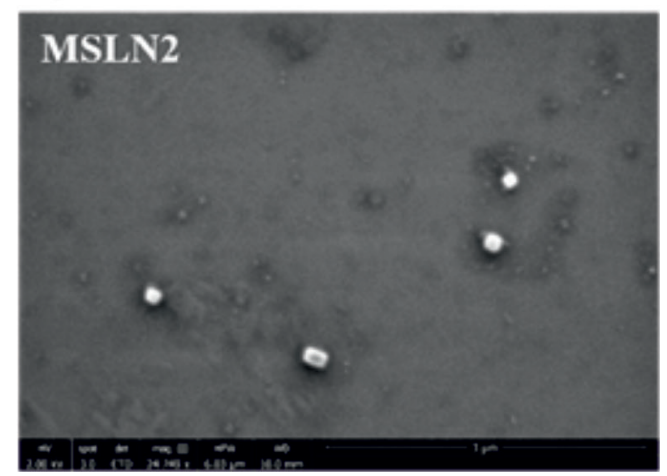

Figure 2. (A) TEM micrograph of $\mathrm{Fe}_{3} \mathrm{O}_{4} @ \mathrm{OA}$ (inset: higher magnification); (B) histogram showing the particle size distribution of the $\mathrm{Fe}_{3} \mathrm{O}_{4} @ \mathrm{OA}$ sample; (C) SEM micrograph of MSLN1; (D) SEM micrograph of MSLN2. 


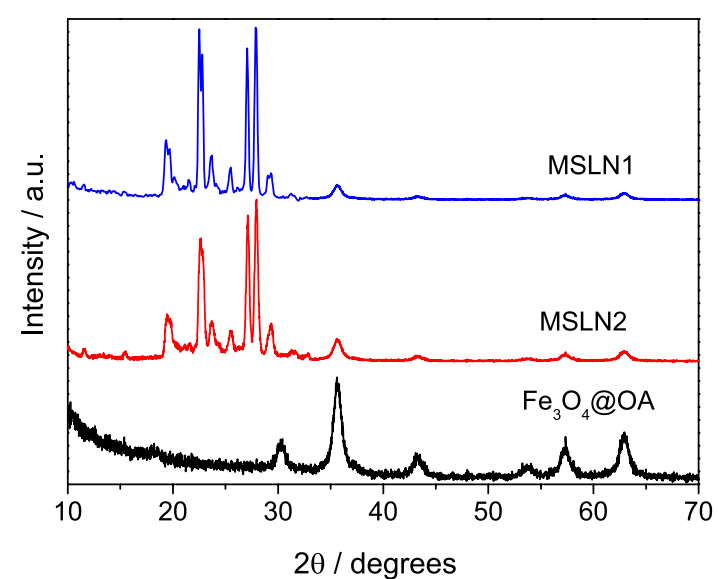

Figure 3. X-ray diffractograms of the samples MSLN1, MSLN2 and $\mathrm{Fe}_{3} \mathrm{O}_{4} @ \mathrm{OA}$.

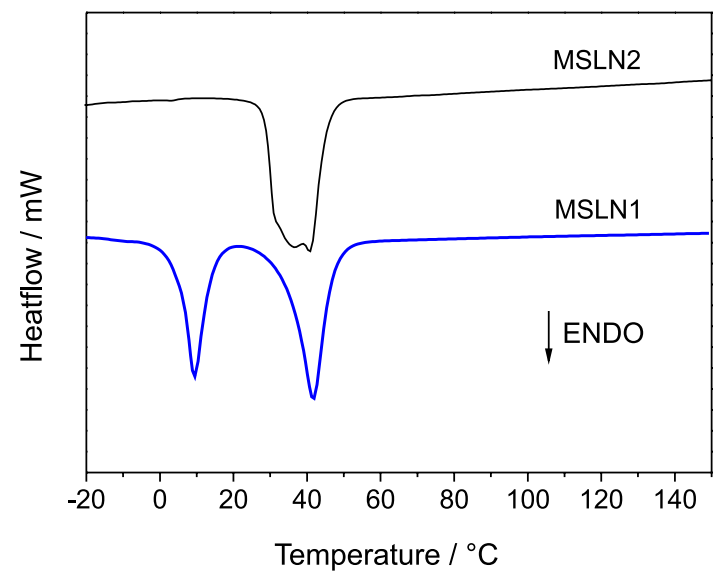

Figure 4. DSC thermograms of freeze-dried samples (MSLN1 and MSLN2).

\section{Magnetic properties of the samples}

Hysteresis loops of $\mathrm{Fe}_{3} \mathrm{O}_{4} @ \mathrm{OA}$, MSLN1 and MSLN2 samples were measured using a vibrating sample

(A)

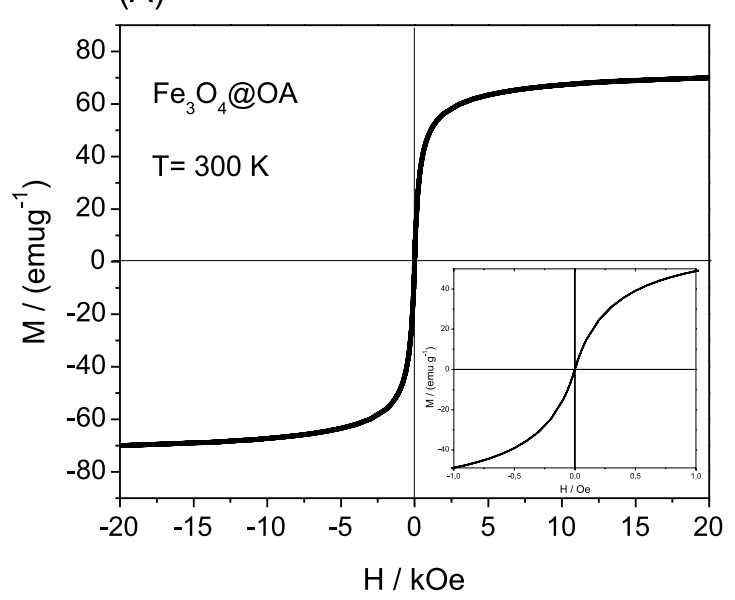

magnetometer (VSM) at $300 \mathrm{~K}$. The magnetization $(\mathrm{M})$ as a function of the applied magnetic field $(\mathrm{H})$ for $\mathrm{Fe}_{3} \mathrm{O}_{4} @ \mathrm{OA}$ showed a characteristic superparamagnetic behavior typical of single-domain magnetite nanoparticles, where both zero remanence and no coercivity are observed (Figure 5A). The saturation magnetization normalized to the total mass (including the non-magnetic mass contribution coming from the organic matter) was as high as $70 \mathrm{emu} \mathrm{g}^{-1}$. Once the organic mass contribution is removed, the saturation magnetization increased up to values very close to those of magnetite bulk, ca. $90 \mathrm{emu} \mathrm{g}^{-1}$, what points to a negligible spin-canting in the atomic surface and emphasizes the long range atomic order due to the surface functionalization with OA. ${ }^{37}$ After the incorporation of $\mathrm{Fe}_{3} \mathrm{O}_{4} @ \mathrm{OA}$ nanoparticles into the triglyceride-based formulations, MSLN1 and MSLN2, the superparamagnetic behavior was preserved, as it comes exclusively from the magnetite nanoparticles. However, the saturation magnetization normalized to the total mass decreased drastically, with values of 2.2 and $2.8 \mathrm{emu} \mathrm{g}^{-1}$ for MSLN1 and MSLN2, respectively (Figure 5B). This was due to the fact that the amount of the organic matter that contributed to the total mass largely increased in the formulations. These values are similar to others reported in the literature for magnetic hybrid systems with biological application. ${ }^{38-40}$ The magnetic character of the MSLN samples, together with the SEM images, further confirms the efficient incorporation of $\mathrm{Fe}_{3} \mathrm{O}_{4} @ \mathrm{OA}$ nanoparticles inside the lipid nanoparticles, which would be presumably embedded in the triglyceride core.

\section{Magnetic hyperthermia measurements}

$\mathrm{The}_{3} \mathrm{O}_{4}$ concentrations used in magnetic hyperthermia tests were 3.3 and $3.8 \mathrm{~g} \mathrm{~L}^{-1}$ for MSLN1 and MSLN2, respectively. The electromagnetic parameters (amplitude

(B)

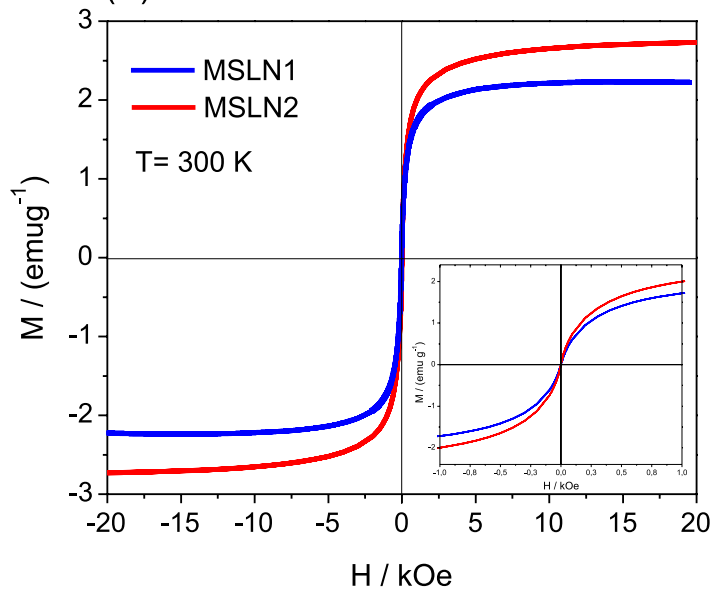

Figure 5. Room temperature hysteresis loops of $(\mathrm{A}) \mathrm{Fe}_{3} \mathrm{O}_{4} @ \mathrm{OA}$ nanoparticles and (B) MSLN1 and MSLN2 samples. Insets are a zoom in the low-field range. 
and frequency of the oscillating magnetic field) used in these experiments are considered within the biologically safe range. ${ }^{41}$ MSLN1 and MSLN2 samples were subjected to a fixed magnetic field of $200 \mathrm{Oe}$, whereas two different frequencies, 688 and $869 \mathrm{kHz}$, were tested. On the one hand, the frequency of $688 \mathrm{kHz}$ caused a temperature increase of $15.5{ }^{\circ} \mathrm{C}$ (MSLN1) and $17.3{ }^{\circ} \mathrm{C}$ (MSLN2) in $15 \mathrm{~min}$. On the other hand, the MSLN1 and MSLN2 samples experienced a temperature increase of 22.7 and $26.1{ }^{\circ} \mathrm{C}$, respectively, when subjected to the frequency of $869 \mathrm{kHz}$ (Figure 6). This increase in the temperature produced by both formulations is the expected effect of the increase of the frequency and there is a linear relationship between the frequency and the heating efficiency.

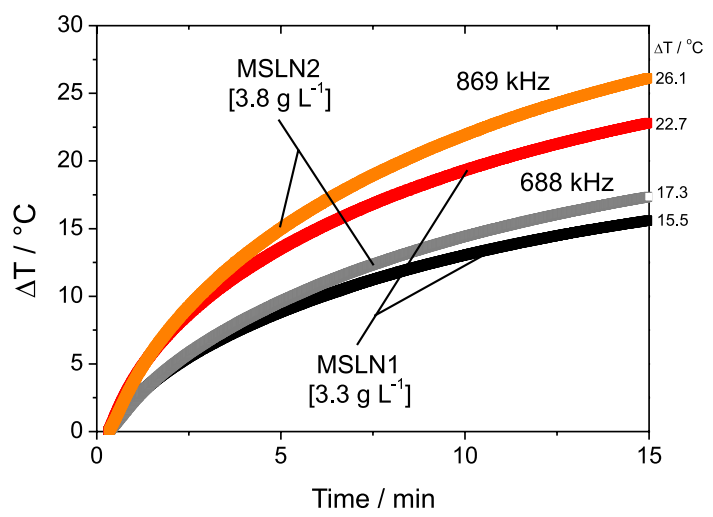

Figure 6. Hyperthermia measurements of the MSLN1 and MSLN2 samples.

These results show that the heating rate induced by the magnetic nanocarriers MSLN1 and MSLN2 under an oscillating magnetic field, can represent a trigger mechanism to induce apoptosis or cellular death in tumoral masses and act as a complementary/alternative cancer treatment. This effect together with the drug release opens a new window of applications for these magnetic lipid systems and show particular promise in cancer treatment, in which the therapeutic action from a drug delivery, together with the additional heat generated in hyperthermia by itself, ${ }^{42,43}$ could induce a more efficient synergetic antitumor action.

\section{In vitro bioactive release studies}

The onco-A encapsulation efficiencies were calculated for the MSLN1 and MSLN2 samples obtaining the values of 71.7 and $73.5 \%$, respectively. Therefore, both systems were effective for the encapsulation of onco-A. Bioactive release studies were performed in MSLN1 and MSLN2 to assess the effect of the lipid matrix on the release profile of an encapsulated drug. Figure 7 shows the release profiles of
onco-A in buffer phosphate medium of $\mathrm{pH}$ 7.4. An initial increase of the drug release rate was observed (burst) when the delivery profile of free onco-A was compared to the situation in which onco-A was incorporated into the triglyceride-based nanocomposites. About $33 \%$ of bioactive release in the first 30 minutes of experiment was observed for free onco-A, and after $5 \mathrm{~h}$ almost all onco-A was released (99\%). In comparison, when onco-A was incorporated into the MSLNs, there was a release of about $8 \%$ within the first $30 \mathrm{~min}$ of experiment for both MSLN1 and MSLN2 samples, followed by a linear drug release rate within the initial $8 \mathrm{~h}$ assay. At this time, onco-A release was of 65 and $46 \%$ for MSLN1 and MSLN2, respectively. From $\mathrm{t}=8 \mathrm{~h}$ on, the concentration of released onco-A increased slowly in both samples, reaching a cumulative release of 73 and 55\% for MSLN1 and MSLN2, respectively, at the end of the drug delivery experiment $(\mathrm{t}=72 \mathrm{~h})$.

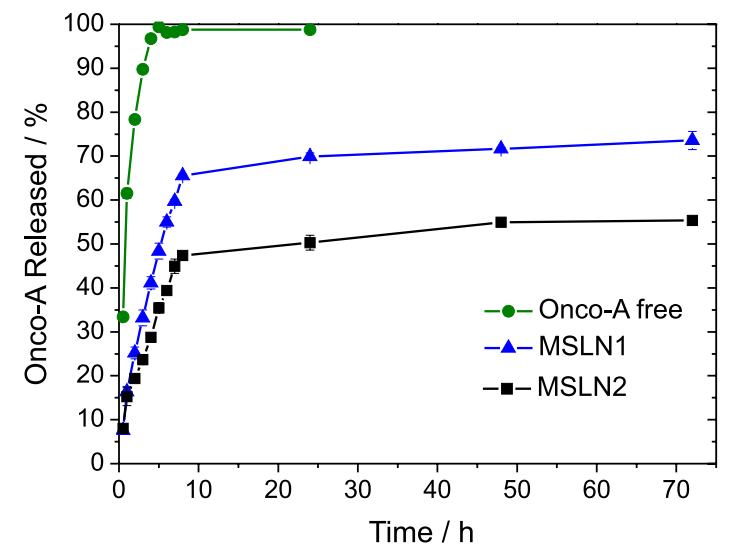

Figure 7. Mean ( \pm standard deviation) percent of onco-A released at $\mathrm{pH} 7.4$.

These results evidence that the MSLNs formulations were able to modify the release profile of onco-A, delaying the release of the drug with time when compared to the non-encapsulated drug delivery profile. Furthermore, the analysis of the release profiles reveals that the triglyceride mixture composition has a direct effect on the onco-A delivery profile. The nanocomposite composed of tricaprin and trilaurin (MSLN1) showed a more pronounced release rate than the triglyceride based formulation composed of tricaprylin and trilaurin (MSLN2) in the first $8 \mathrm{~h}$, in addition to a higher amount of drug released during this time (ca. 19\% difference). However, in the time range from $\mathrm{t}=8 \mathrm{~h}$ up to $\mathrm{t}=72 \mathrm{~h}$, the amount of drug released represents about a $10 \%$ in both nanocomposites. The observed difference between the drug delivery profiles of both nanocomposites lies in the first $8 \mathrm{~h}$, which seems to be related to the distribution of the onco-A within the lipid nanoparticles. 
Table 1. Results of curve fitting of the in vitro onco-A released at $\mathrm{pH} 7.4$

\begin{tabular}{lcccc}
\hline \multirow{2}{*}{ Sample } & \multicolumn{3}{c}{ Correlation coefficient $\left(\mathrm{r}^{2}\right)$} & \multirow{2}{*}{ Release exponent (n) } \\
\cline { 2 - 4 } & Zero-order & Higuchi & Korsmeyer-Peppas & 0.321 \\
Free onco-A & 0.8976 & 0.9807 & 0.932 & 0.287 \\
MSLN1 & 0.9763 & 0.9813 & 0.989 & 0.238 \\
MSLN2 & 0.9694 & 0.9819 & 0.977 & 0.23 \\
\hline
\end{tabular}

The reason could lie in the different phase structure that MSLN1 and MSLN2 show in their lipid core. The plausible formation of domains of oil inside the solid lipid matrix in MSLN1 as consequence of the solubility of the liquid lipid tricaprylin in the solid tricaprin matrix, as deduced from the DSC results, could favor a greater interaction of onco-A with the hydrophobic core of the MSLN2 nanocomposite. The in vitro bioactive release data from onco-A encapsulated MSLNs were evaluated kinetically using various mathematical models, such as zero order, Higuchi and Korsmeyer-Peppas models. The results of the data fitting into these above-mentioned mathematical models are given in Table 1. In all cases, the values for $n$ were smaller than 0.5 , meaning that onco-A release occurs by diffusion (Fickian model). Several other systems based on SLN described in the literature follow the same release pattern found in this study. ${ }^{44,45}$ This indicates that the release profile of the active compound is controlled by diffusion through the lipid core and, subsequently, by diffusion through cellulose membrane.

\section{Cytotoxicity of MSLNs in human neutrophils}

The potential toxic effects of the MLSNs in human neutrophils were investigated by measurements of $\mathrm{LDH}$ activity in the cell suspensions. The measurement of LDH activity, enzyme present in the cell cytoplasm, is a marker of intact membrane with considerable sensitivity. In this study, the MSLNs associated with oncocalyxone-A did not affect the cell viability assessed by LDH activity when compared with a control group (HBSS) (Figure 8), suggesting the absence of toxicity on the cell membrane of human neutrophils.

\section{Conclusions}

Magnetic solid lipid nanoparticles based on triglycerides mixtures were successfully synthesized by emulsificationsolvent evaporation method. The magnetic MSLN1 and MSLN2 nanocomposites were colloidally stable in water and showed an average particle size below $200 \mathrm{~nm}$. Such systems are presented as potential candidates for

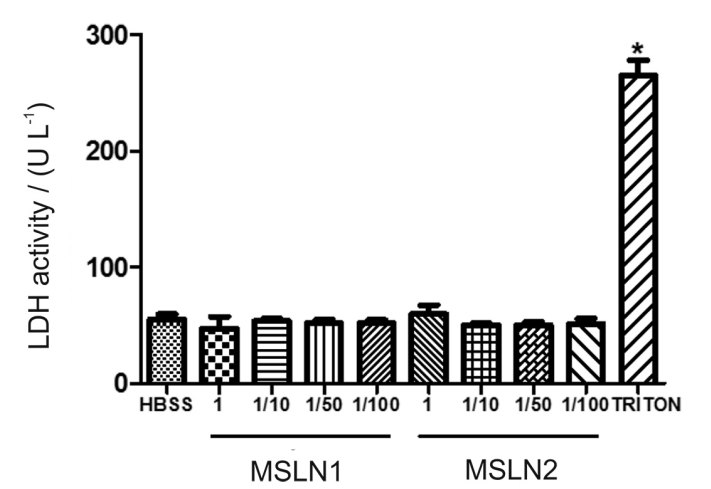

Figure 8. Evaluation of MSLN1 and MSLN2 toxicity measured by LDH activity in human neutrophils. Results represent means \pm the standard error of the mean (SEM) $(p<0.05$; ANOVA and Tukey as the post hoc test).

therapeutic applications due to promising results in magnetic hyperthermia and drug release of onco-A. On the one hand, in vitro drug delivery assays showed that the MSLNs formulations were able to modify the release profile of onco-A, delaying the drug delivery and evidencing the effect of the triglyceride mixture composition on it. On the other hand, the good hyperthermia response of the nanocomposites under an oscillating magnetic field provides MSLNs with high promise as heat generating sources in magnetic hyperthermia. In addition, the MSLNs formulations did not affect the cell viability as measured by LDH activity, suggesting the absence of toxicity on the cell membrane of human neutrophils. Therefore, the triglyceridebased magnetic nanocomposites open new perspectives for biomedical applications through the synergism between the therapeutic action of bioactive compounds and hyperthermia properties from iron oxide nanoparticles.

\section{Acknowledgments}

The authors thank the Brazilian funding agency CAPES/INL (Process No. 0075/14-0) for the financial support. The authors are also grateful to National System of Nanotechnology (SisNano). The authors thank Dr Carlos Rodríguez-Abreu for fruitful discussions. M. B. would like to thank ERDF (European Regional Development Fund) under grant P.O Norte CCDR-N/ON.2 Programme. J. G. also thanks the European Union's Seventh Framework 
Programme for research, technological development and demonstration under grant agreement No. 600375.

\section{References}

1. Colombo, M.; Romero, S. C.; Casula, M. F.; Guyérrez, L.; Morales, M. P.; Bohm, I. B.; Heverhagen, J. T.; Prosperi, D.; Park, W. J.; Chem. Soc. Rev. 2012, 41, 4306.

2. Li, Z.; Kawashita, M.; Araki, N.; Mitsumori, M.; Hiraoka, M.; Doi, M.; Mater. Sci. Eng., C 2010, 30, 990.

3. Hao, R.; Xing, R.; Xu, Z.; Hou, Y.; Gao, S.; Sun, S.; Adv. Mater. 2010, 22, 2729.

4. Yoo, D.; Lee, J. H.; Shin, T. H.; Cheon, J.; Acc. Chem. Res. 2011, 44, 863.

5. Majidi, S.; Sehrig, F. Z.; Farkhani, S. M.; Goloujeh, M. S.; Akbardazeh, A.; Artif. Cells, Nanomed., Biotechnol. 2016, 44, 722.

6. Sharma, R. K.; Dutta, S.; Sharma, S.; Zboril, R.; Varma, R. S.; Gawande, M. B.; Green Chem. 2016, 18, 3184.

7. Calero, N.; Munoz, J.; Ramírez, P.; Guerrero, A.; Food Hydrocolloids 2016, 24, 659.

8. Corato, R. D.; Bigall, N. C.; Ragusa, A.; Dorfs, D.; Genovese, A.; Marotta, R.; Manna, L.; Pellegrino, T.; ACS Nano 2011, 5, 1109.

9. Soares, P. P.; Barcellos, G. S.; Petzhold, C. L.; Lavayen, V.; J. Phys. Chem. Solids 2016, 99, 11.

10. Souto, E. B.; Severino, P.; Santana, M. H. A.; Pinho, S. C.; Quim. Nova 2011, 34, 1762.

11. Müller, R. H.; Radtke, M.; Wissing, S. A.; Int. J. Pharm. 2002, 242,121

12. Martins, S.; Thoi, I.; Reimold, I.; Fricker, G.; Souto, E.; Ferreira, D.; Brandl, M.; Int. J. Pharm. 2012, 439, 49.

13. Ghadiri, M.; Vatanara, A.; Doroud, D.; Roholamini, N. A.; Int. J. Pharm. 2012, 424, 128.

14. Kheradmandnia, S.; Vasheghani-Farahani; Nosrati, M.; Atyabi, F.; Nanomedicine 2010, 6, 753.

15. Sinha, V. R.; Srivastava, S.; Goel, H.; Jindal, V.; Indian J. Adv. Plant Res. 2010, 1, 212.

16. Souto, E. B.; Müller, R. H.; Encycl. Nanosci. Nanotechnol. 2011, 23, 313.

17. Tamjidi, F.; Shahedi, M.; Varshosaz, J.; Nasirpou, A.; Innovative Food Sci. Emerging Technol. 2013, 19, 29.

18. Mohtar, N.; Khan, A. K. N.; Darwis, Y.; Int. J. Prod. Res. 2015, 14, 989.

19. Naguib, Y. W.; Rodriguez, B. L.; Li, X.; Hursting, S. D.; Williams, R. O.; Cui, Z.; Mol. Pharmaceutics 2014, 11, 1239.

20. Esposito, E.; Fantin, M.; Marti, M.; Drechsler, M.; Paccamiccio, L.; Mariani, P.; Sivieri, E.; Lain, F.; Menegatti, E.; Morari, M.; Cortesi, R.; Pharm. Res. 2008, 25, 1521.

21. Grillone, A.; Riva, E. R.; Mondini, A.; Forte, C.; Calucci, L.; Innocenti, C.; Fernandez, C. J.; Cappello, V.; Gemmi, M.;
Moscato, S.; Ronca, F.; Sacco, R.; Mattoli, V.; Ciofani, G.; Adv. Healthcare Mater. 2015, 4, 1681.

22. Shen, G.; Liang, C.; Ge, Q.; Du, B.; Zhengzhou Daxue Xuebao, Lixueban 2010, 31, 16.

23. Zhao, S.; Zhang, Y.; Han, Y.; Wang, J.; Yang, J.; Pharm. Res. 2015, 32, 482 .

24. Reddy, L. H.; Arias, J. L.; Nicolas, J.; Couvreur, P.; Chem. Rev. 2012, 112, 5818.

25. Terreno, E.; Castelli, D. D.; Viale, A.; Aime, S.; Chem. Rev. 2010, 110, 3019.

26. Laurent, S.; Dutz, S.; Hafeli, U. O.; Mahmoud, M.; Adv. Colloid Interface Sci. 2011, 166, 8.

27. Meenach, S. A.; Hilt, J. Z.; Anderson, K. W.; Acta Biomater. 2010, 6, 1039.

28. Barreto, A. C. H.; Santiago, V. R.; Mazzetto, S. E.; Denardin, J. C.; Lavin, R.; Mele, G.; Ribeiro, M. E. N. P.; Vieira, I. G. P.; Gonçalves, T.; Ricardo, N. M. P. S.; Fechine, P. B. A.; J. Nanopart. Res. 2011, 13, 6545.

29. Jadhav, N. V.; Prasad, A. I.; Kumar, A.; Mishra, R.; Dhara, S.; Babu, K. R.; Prajapat, C. L.; Misra, N. L.; Ningthoujam, R. S.; Pandey, B. N.; Vatsa, R. K.; Colloids Surf., B 2013, 108, 158.

30. Nayak, A.; Laha, B.; Sen, K.; Acta Pharm. 2011, 61, 25.

31. Ferrero, C.; Muñoz-Ruiz, A.; Jiménez Castellanos, M. R.; Int. J. Pharm. 2000, 202, 21.

32. Lucisano, Y. M.; Mantovani, B.; J. Immunol. 1984, 132, 2015.

33. Kabeya, L. M.; Kanashiro, A.; Azzolini, A. E.; Soriani, F. M.; Lopes, J. L.; Lucisano-Valim, Y. M.; Res. Commun. Mol. Pathol. Pharmacol. 2002, 111, 103.

34. León, L.; Bustamante, A.; Osorio, A.; Olarte, G. S.; Valladares, L. S.; Barnes, C. H. W.; Majima, Y.; Hyperfine Interact. 2011, 202, 131 .

35. Jenning, V.; Mäder, K.; Gohla, S. H.; Int. J. Pharm. 2000, 205, 15.

36. Üner, M.; Radtke, M.; Wissing, S. A.; Encycl. Nanosci. Nanotechnol. 2007, 10, 43.

37. Guardia, P.; Batlle-Brugal, B.; Roca, A. G.; Iglesias, O.; Morales, M. P.; Serna, C. J.; Labarta, A.; Batlle, X.; J. Magn. Magn. Mater. 2007, 316.

38. Escalona, M. M.; Fernández, E. S.; Prados, J. C.; Int. J. Pharm. 2016, 504, 11.

39. Bakandritsos, A.; Mattheolabakis, G.; Zboril, R.; Bouropoulos, N.; Tucek, J.; Fatouros, D. G.; Avgoustakis, K.; Nanoscale 2010, 2,564 .

40. Vilos, C.; Gutierrez, M.; Escobar, R. A.; Morales, F.; Denardin, J. C.; Velasquez, L.; Altbir, D.; Electron. J. Biotechnol. 2013, $16,1$.

41. Bañobre-López, M.; Teijeiro, A.; Rivas, J.; Rep. Pract. Oncol. Radiother. 2013, 18, 397.

42. Liu, X. L.; Choo, E. S. G.; Ahmed, A. S.; Zhao, L. Y.; Yang, Y.; Ramanujan, R. V.; Xue, J. M.; Fan, D. D.; Fan, H. M.; Ding, J.; J. Mater. Chem. B 2014, 2, 120. 
43. Li, Z.; Kawashita, M.; Araki, N.; Mitsumori, M.; Hiraoka, M.; Doi, M.; Mater. Sci. Eng., C 2010, 30, 990.

44. Tiyaboonchai, W.; Tungpradit, W.; Plianbangchang, P.; Int. J. Pharm. 2007, 337, 299.
45. Kashanian, S.; Azandaryani, H. A.; Derakhshandeh, K.; Int. J. Nanomed. 2011, 6, 1.
Submitted: October 20, 2016

Published online: January 26, 2017 